\title{
Dynamic Capabilities as Context: the Role of Decision, System and Structure
}

Paper for conference “Dynamic Capabilities and Beyond” St Petersburg, December 2007

\author{
Neil Kay \\ neilkay@aol.com \\ Department of Economics \\ Sir William Duncan Building \\ University of Strathclyde \\ 130 Rottenrow \\ Glasgow G4 0GE \\ Scotland, UK \\ $\mathrm{t}:+44(0) 1415483842$ \\ f: $+44(0) 1415484445$
}

First draft $29^{\text {th }}$ October 2007 


\begin{abstract}
In this paper we look at some implications of the role of dynamic capabilities in enabling strategic decision-making in the firm. It is argued that properly specifying questions relating to dynamic capabilities raises questions of what is involved in strategic decisions, which in turn inevitably involves (or should involve) consideration of the complementary roles of nondecomposability and decision processes. This entails a reappraisal of how and where established frameworks may or may not be of relevance in this context, and invites consideration of how economics perspective should be framed to deal with such issues.
\end{abstract}




\section{Dynamic Capabilities as Context: the Role of Decision, System and Structure}

\section{Introduction}

The theme of this conference, "Dynamic Capabilities and Beyond” is amenable to a variety of interpretations, some of which are reflected in the contributions of other papers. In this paper we shall look at some aspects of the "Beyond" part of the theme, in particular issues relating to what dynamic capabilities may be said to be for, that is the enabling of strategic decision-making in the firm.

The idea that capabilities can be sources of competitive advantage draws on several strands in the preceding literature, and it is appropriate with an efficiency-based perspective that much of this prior literature is predominantly written by economists, or from an economics perspective (e.g. Nelson and Winter, 1982; Dosi, 1982; Langlois, 1992; Langlois and Robertson, 1995; Penrose, 1959; Porter, 1985; Richardson, 1972; Rumelt, 1984; Schumpeter,1942; Teece 1986a and 1986b).

An economics perspective can be a powerful tool for investigating questions of sources of competitive advantage. At the same time, those of us coming from an economics tradition carry with us certain baggage and frames of reference that are difficult to shake off, and these in turn are likely to have coloured the subsequent analysis of dynamic capabilities and their implications (much of this subsequent research again being done by economists, or from an economics perspective).

Just as members of a quarrelsome family may see only their differences while outside observers may more easily see the ties that bind them together, so the kinship relations and common belief systems shared by neoclassical and heterodox economists alike run much deeper than is often apparent to members of this extended and argumentative tribe. Anyone who doubts this might profit from reading the Nobel citations for Ronald Coase, Herbert Simon and Douglass North, amongst others. Each of these made seminal, indeed revolutionary and lasting contributions to economics science. Yet while the citations rightly laud the originality of the laureates and their departures from orthodoxy, time and again the citations also record how their respective contributions may be regarded as not a substitute for orthodoxy, but as a complement to it, and even in some cases as an extension of it into new areas. For example, the core importance and universal relevance of such concepts as efficiency, individual choice, self interest and rationality may be disputed to a greater or lesser extent and from time to time by non-economists, but is rarely disputed by members of the sect itself, at least not by those who fear excommunication ${ }^{1}$.

The relevance of this for the present paper is that frames of reference can of necessity limit as well as sharpen perception, and as far as dynamic capabilities is concerned, there are two potentially limiting influences that an economics perspective can bring to bear here. The first is the role of decision. In economics, decision and choice are synonymous; in practice strategic decisions of the type that may be associated with the deployment of 
dynamic capabilities can involve processes that unfold over a considerable period of time. The second potentially limiting influence is reductionism, which in economics means placing individual units centre stage and treating higher levels as simple aggregates of lower level elements, obscuring systemic patterns or structures of potential relevance to behaviour in the process.

Perhaps not surprisingly, it was Simon who was the first to bring both issues on to the economic agenda, at least in a well-publicised form that was palatable to economists. As Williamson is careful to note when he himself ventures into what would be (for an economist) dubious territory, rationality (albeit of the bounded variety) was at the heart of Simon's contribution (Williamson, 1985. p. 11), while he notes that Simon (1976) "makes repeated reference to the criterion of efficiency" (Williamson, 1985, p. 11).

In fact, Simon's “Administrative Behavior” is part sub-titled; “A Study of DecisionMaking Processes..." (italics added), and he starts by asking the question;

“Who really makes the decisions?” Such a question is meaningless - a complex decision is like a great river, drawing from its many tributaries the innumerable component premises of which it is constituted. Many individuals and organization units contribute to every large decision, and the problem of centralization and decentralization is a problem of arranging this complex system into an effective scheme" (Simon, 1976, p. xii, italics in original).

Decisions seen as processes, rivers and complex systems? No wonder many economists who had got as far as this would nod their head in agreement that the question posed was meaningless, and that Simon's description of decisions, while poetic (and therefore not economic), would be difficult to operationalise. If they did follow up on parts of Simon's analysis they tended to focus on Simon's analysis of individual decision premises which made up the bulk of the first part of the book, noting as they did Simon's treatment of the words "decision" and "choice" as interchangeable and referring to "selection" (Simon, 1976, p.4). The integrative chapters XI and XII" ${ }^{2}$, which brought these various elements together in an analysis of complex decision processes as a whole, and which was to be later refined into an analysis of "nearly decomposable systems" (Simon, 1981), could be safely ignored.

Indeed, to the extent that, economists were familiar with Simon's work, it was more likely to be from his QJE article (Simon, 1955) which emphasised individual (boundedly) rational choice behaviour ${ }^{3}$. Once the small step for reality (but giant leap for economists) of acknowledging cognitive and language limits on decision-making had been taken, even the most orthodox of economists could see that satisficing behaviour had a certain efficiency-based logic and rationality to it.

As for complex, nearly decomposable systems, these also found their way into the economics lexicon, but typically with more emphasis on the "decomposable" part than the "nearly". For example, as noted above, Williamson acknowledges the debt he owes to 
Simon and indeed dedicates his 1985 work to Simon as one of his teachers ${ }^{4}$. However, when he raises Simon's principle of near decomposability, he tends to discuss it in the context of the conglomerate (e.g. Williamson 1985, 281-90), the most decomposable of all diversified strategies, as the relative ease with which it can generally acquire and dispose of assets (divisions) helps demonstrate. The advantage of focussing on the conglomerate is that it helps reduce the "nearly" part of Simon's "nearly decomposable" system to little more than the working of an internal M-form capital market, with constituent elements being treatable as quasi-autonomous divisions, often as profit centres (Williamson, 1985, 287-288). By contrast, based largely on Chandler (1977) Williamson notes that the "(indecomposable) U-form" (Williamson, 1985, p.283) was subject to "bureaucratic distortions" (Williamson, 1985, p.95) with centralized decisions meaning that "bounds on rationality were reached as the U-form structure laboured under a communication overload” (Williamson, 1985, p.280-281). These efficiency problems were solved or mitigated by the M-form structure which "recognized essential decomposability, thus rectifying the overcentralization condition in the U-form enterprise” (Williamson, 1985, p. 296)

It is difficult to escape the conclusion that all this has the flavour of "decomposable good" and "indecomposable bad" about it, and indeed this can be plausible and reassuring for all those of us who were nurtured in a respectable economic neighbourhood. Decomposability is a prerequisite for individual units to aggregate, with the resulting power this gives economics to move easily from micro to macro levels. Take away decomposability, and you compromise or complicate the applicability and usefulness of the standard economic tool kit lovingly and carefully developed by generations of economists.

The problem is that this approach leaves us with little to talk about as far as the organization and strategy of the firm is concerned, and we shall argue below that this also holds by extension to the role and relevance of dynamic capabilities in the firm.

Firstly, indecomposabality or limited decomposability is the norm, decomposability (at least of the extreme kind that Williamson was describing) is the exception. Most firms are not M-forms, indeed although the form was invented in the early Twentieth Century (Chandler, 1977) it only became widely diffused in the late Twentieth Century and even then was largely restricted to the large diversified corporations (Channon, 1973; Dyas and Thanheiser, 1976; Rumelt, 1986). Despite the M-form's decomposability advantages, the Uform is still the structure of choice for most small and medium sized organisations, which of course means most firms.

Secondly, even amongst large diversified firms, the majority of which tend to have adopted the M-form structure, the conglomerate is a relatively rare diversification strategy. By 1993 it constituted 14\% of the largest 100 French industrial firms, 32\% of the 100 largest German industrial firms and 24\% of the 100 largest UK industrial firms (Whittington and Mayer, 2000, pp.126-43). The majority of even the largest industrial firms in each country were either relatively specialised or related diversifiers. 
Thirdly, while it is not too difficult to make a case (and find evidence) for the superior performance of the conglomerate's highly decomposable M-form internal market when compared to U-form and external capital market alternatives, that runs into the problems of limited comparators (Kay, 1997, pp.58-61). If a case is to be made for such extremely decomposable strategies, then it has also to be made against less decomposable strategies such as the related diversifiers. Unfortunately here the argument and evidence is far from clear, and ranges from descriptions of conglomerates as "hopeful monsters" with limited chances of long term survival in a evolutionary context (Dosi et al 1992; Teece et al 1994), to qualified attempts at rehabilitating their reputation (e.g. Whittington and Mayer, 2000, p.216).

Fourthly, even conglomerates tend to be built around indecomposable or nearly decomposable systems and sub-systems. We shall look in more detail at Mitsubishi Corporation later and start with the general description of it as a conglomerate. However, defining it as a conglomerate is rather like describing an iceberg in terms of the tip above the surface. That could be as ill-advised a convention in strategic management as it would be in maritime navigation. Not far below the surface of the multi-layered complex system that is Mitsubishi we encounter richly linked and inter-related subsystems that are best only partly decomposable, if that. Conglomerates do not avoid issues of indecomposability, they just hide them rather better than most, deferring them to just a little further down the hierarchy than is the case for their related comparators.

In short, extreme decomposability of the kind associated with strategies and structures such as the M-form conglomerate is very unusual, is of questionable merit considered in performance terms, and even where it is found it tends to refer to only very limited aspects of the organisational hierarchy.

Looking for sound answers to strategic management issues by identifying conditions of extreme decomposability is like looking for our watch under the lamppost even though we knew we lost in somewhere in the darkness. Decomposability may help shine the bright light of extant economic theory, but if the only real answers are to be found somewhere in the darkness where our existing tools do not shine much light, then that is where we have to look. Nondecomposability or partial decomposability lies at the heart of the nature of the firm (Langlois, 2002) and is where we must venture if we want to do even a half-decent job of analysis

It is important to emphasise that this does not negate or even downgrade contributions limited to framing decisions as choice-based, or looking at isolated individual element without reference to any relations they may have within a wider system. Simon himself signposted how valuable contributions based on individual choices could be. What it does mean is that there may be circumstances in which looking at phenomena from the perspective of both process and system may help illuminate analysis. We will also argue that dynamic capabilities are themselves examples of just such phenomena which would benefit from such a perspective, indeed which require just such a perspective. While we may only be able to hint at the nature of Simon's "great river" of complex decision, the 
fundamental nature of the firm lies in the navigation and exploration of such entities, not in the momentary dipping of toes into minor tributaries.

In the next section we shall consider the possible relevance of seeing decision as process for dynamic capabilities, while in Section 3 we pursue systemic aspects and implications, and we finish with a short concluding section. .

\section{Dynamic capabilities and decisions as process}

While there has been much interest in dynamic capabilities in recent years, there is by no means unanimity as to what is meant by the concept, let alone its implications and significance. In reviewing the literature on dynamic capabilities, Zahra et al (2006) find it riddled with inconsistencies, overlapping definitions, and contradictions, this reflected in nine different definitions they cite from the extant literature over the previous decade. Rather than try to aggregate, average or distil these varied representations, we shall stick to original sources as far as possible and treat dynamic capabilities as emphasizing the key role of strategic management in appropriately adapting, integrating and reconfiguring internal and organizational skills, resources and functional competences; where a turbulent environment means time to market, timing, and accelerating technological change are all important; and where the nature of future competition and markets is difficult to determine (Teece and Pisano, 1994; Teece, Pisano and Shuen, 1997)

Eisenhardt and Martin (2000) argue that dynamic capabilities are a set of specific and identifiable processes such as product development, strategic decision making and alliancing. They argue that while these capabilities may be idiosyncratic and path dependent in both their origins and specific characteristics, nonetheless they can have significant commonalities across firms (benchmarked as "best practice”) and in those crucial respects their sources of competitive advantage are generally replicable and imitable, this echoing reservations expressed about the notion of distinctive competences as being unique and irreplaceable as expressed in Kay (1997, pp.14-16). Eisenhardt and Martin argue that dynamic capabililities display the property of equifinality, that is, firms starting from different starting points and following unique paths nonetheless end up with capabilities that are similar in terms of key attributes; in open systems terms, the same final system state may be reached from various initial conditions and via different sequences of intermediate system state.

The concept of equifinality and its implications has become a major topic in a number of fields in recent years, including the study of organizations (e.g. see Gresov and Drazin, 1997). Eisenhardt and Martin's arguments regarding equifinality in the context of the development of dynamic capabilities are supported by earlier $\mathrm{PhD}$ research also published in book form ${ }^{5}$ which looked at the allocation of resources to $R \& D$ in the firm and found strong evidence of equifinality in patterns of R\&D budgeting across and within industries, and between firms. 
Clearly if that was all there was to say about the sources of competitive advantage, then the logical conclusion of Eisenhardt and Martins'argument could be described as a lazy capabilities version of the efficient capital market hypothesis ${ }^{6}$. If (a) competitive advantage and economic rents are attributable to dynamic capabilities and (b) dynamic capabilities are in general replicable and imitable, then it follows that; (c) dynamic capabilities cannot be a source of sustainable competitive advantage. If dynamic capabilities provide a source of economic advantage, there will be incentives for others to replicate and adopt them, in turn eroding the advantages they provided to the originator, though the process may be "lazy" providing temporary rents and take some time to unwind.

Eisenhardt and Martin avoid this trap by arguing that dynamic capabilities such as in product development, strategic decision making and alliancing may be necessary but not sufficient for sustainable competitive advantage, which may also depend on the resource configurations that managers can draw on and build using these capabilities. Teece, Pisano and Shuen also emphasise that dynamic capabilities involve "the development of management capabilities, and difficult-to-imitate combinations of organizational, functional and technological skills” (1997, 510).

But if dynamic capabilities are to help organizations in "adapting, integrating and reconfiguring” (Teece and Pisano, 1994, p. 537), then decisions have to be at the heart of this process. A “capability” generally refers to a potential or capacity for action, but unless decisions are taken as to how to deploy that capability in particular contexts, then capabilities are worse than useless, they are simply wasteful and costly absorbers of resources.

All this might seem obvious but in the field of the economics of organizations it is possible to both downplay and ignore the role of decisions. For example, Williamson argues that Simon's "decision premise" is too micronalytic and never operationalized in such a way as to give it broad and general application (Williamson, 1996, p. 44). He sees Simon's applications of bounded rationality as simply reflected in "the satisficing approach" which he regards as a dead end as a research tradition and "not broadly applicable” (Williamson 1996, p. 37). This manages to ignore approaches to organizational decision processes such as garbage can modelling (e.g. Cohen et al, 1972) which explicitly build their approaches to decision-making on Simon's earlier work. This goes along with a general ignoring of the role of decisions in transaction cost economics. Remarkably, it is possible to study the transaction cost canon (e.g. Williamson 1975; 1985; 1996) and find little, if any, direct evidence of decisions being made, and if they are made, how they are made (individuals are opportunistic and efficient outcomes tend to win out, but there is little evidence or discussion as to whether individuals satisfice, optimise, or resort to other decision criteria).

Neglecting decisions in the study of organization is like ignoring “to be or not be?” in the study of Hamlet. It may not be easy to follow and analyse the decision process contingent on Hamlet's dilemma, indeed it may not be easy to work out what the decision framed in this ambiguous question actually is; whole books have been written to inform and 
confuse on both topics. Hamlet is clearly dynamically capable ("our valiant Hamlet For so this side of our known world esteemed him") ${ }^{7}$ and opportunistic ("The play's the thing, wherein I'll catch the conscience of the king") ${ }^{8}$, but Hamlet without decisions would indeed be Hamlet without the prince.

The same argument holds for organizations, notwithstanding Williamson's criticisms of use of decisions in this context, criticisms which are really aimed at the wrong target. That being the case, it is important to establish what decisions might actually look like in the context we are concerned with here, that is, dynamic capabilities.

The first question we have to dispense with here is that the economics of organization is an area (much like many others) where ambiguity in the use of terms is endemic and can be problematic (Kay, 2008, forthcoming). For our present purposes, the problem lies here with the definition and interpretation of "decision”.

Economists study "how people make decisions" (Mankiw, 1998, p.4) and Samuelson in an early edition of his classic work stated; "Economics is the study of how people and society end up choosing ....” (Samuelson, 1976, p.3, italics in original). By the twelfth edition (with William Nordhaus), Samuelson was giving as one of the popular definitions of economics "economics is the science of choice” (Samuelson and Nordhaus, 1985, p.4)

Most economists, especially those reared in an orthodox neoclassical tradition, are likely to find those definitions reasonable and uncontroversial, though most are likely go on to add more flesh and blood to these skeletons by adding references to notions of scarcity, resources, etc. Economics is about decisions and choices, more precisely decisions in this view of economics are choices. It is the act of selection from alternatives made by individuals and institutions, and if they are being rational, they will select the option that best serves their interests.

In reality, “decision” is one of a family of words in the English language which are intrinsically ambiguous and can be used to refer to either an act or a process (other examples in this lexically fungible extended family include "innovation", "invention" and “competition”. To characterise the contrast between Simon and, say, Samuelson as simply a contrast between types of choice (satisficing and optimising) - which is effectively what Williamson did - is to make the same mistake that many have made in characterising the contrast between Schumpeter (1942) and neoclassical theory as simply a reflecting difference in emphasis in types of competition (technology versus price competition). Simon and Schumpeter shared a concern with something lacking in neoclassical conceptions, a concern with processes.

We shall consider the role of decisions in dynamic capabilities in terms of processes, and to do so we shall consider what kind of features of decision processes we might expect to find associated with the types of dynamic capabilities cited by Eisenhardt and Martin, that is, strategic decision making, alliancing and product development.

An early analysis of one form of strategic decision making processes was provided by 
Loasby (1967) who looked at long-range formal planning processes as high level routines in the firm (anticipating, in some respects, features observed and analysed by Nelson and Winter, 1982; and Winter, 2003). For Loasby there were three main aspects to the role that devices such as long-range formal planning could play, firstly it could help signpost the future implications of present decisions. Secondly, it could help identify the present implications of future possibilities. Thirdly, it provided a systematic structure linking present commitments to future possibilities.

These are quite different perspectives on decisions from the conventional economics where future and present implications collapse together into a single unified measure of present value. Once you have identified present value, you have eliminated the future (otherwise its retention would mean double counting). On the other side of the coin, (conventional) economics' treatment of history starts from the principle that you ignore the past (bygones are bygones and sunk costs are irrelevant). By ignoring the past and eliminating the future, conventional economics succeeds in banishing time altogether.

By contrast, Loasby makes explicit the idea of long range planning decisions as a process, with present and future being linked together by the glue of systematic structures and organizational routines. Long range formal planning is only one way that strategic decisions may be formulated, pursued and executed, garbage can modelling (e.g. Cohen et al, 1972) is a quite different approach to how such processes may be embodied in practice. Scenario planning is one example of a long range planning process and dynamic capability that provided competitive advantage for Royal Dutch / Shell. The technique had military origins in the Cold War with US strategists looking at the present and future implications of possible events and conflicts, including nuclear war. Royal Dutch Shell was a leading pioneer of its application in the commercial sphere. A scenario which had been fed into the planning system was; what would happen, and what would need to be decided (now and in the future), if the OPEC countries forced a sharp rise in the price of oil?

That scenario came about with the oil crisis in 1973. Royal Dutch Shell was the best prepared of all the major oil companies to deal with the crisis, and its preparedness, due in large part to scenario planning, helped propel the company up the ranks of major industrial companies. It rose from being one of the weaker of the majors to a leading position.

If there ever was an instance of a dynamic capability that generated competitive advantage, then Royal Dutch Shell's scenario planning was surely that capability. However, this dynamic capability was both imitable and imitated. We know this because Peter Schwartz who was responsible for scenario planning in Royal Dutch / Shell in the early Eighties left the company to co-found a consultancy (Global Business Network) to help other companies do exactly that ${ }^{9}$. That dynamic capability was, at least in large part, both detachable and replicable ${ }^{10}$, consistent with Eisenhardt and Martins'argument (above) regarding the general imitability of dynamic capabilities. 
Such capabilities may create the forum of strategic decisions, but how long do strategic decision making processes take and how complex do they get? Obviously the answer varies from case to case, but broad patterns are identified by Hickson et al. (1986), following earlier work by Mintzberg et al (1976). Hickson et al looked at 150 strategic decisions made by large organizations over a period of ten years and found that the time taken from start to finish for such decisions ranged from about a month to four years. The average duration was a little over a year (Hickson et al., pp. 100-102). Olsen's (1976a and 1976b) studies of two major decisions fits into these time frames, with a ninemonth decision making process for the appointment of a new dean at a major US public university (1976a) and a 31 month period to reorganise a science department in a Norwegian university, starting with the proposition by the Administrative Board of the School and ending with the senor governing body accepting the Department of Physics' proposal for reorganization (1976b).

Hickson et al also found most of their strategic decisions were characterized by a gestation period during which the strategic decision was being formulated and specified, which about doubled the total duration of decision-making (p. 107). They also found that numerous internal and external units tended to be involved in such decisions, the average number of major units involved per decision was seven (Hickson et al., p. 46). They also found that these decisions typically set off 'waves' of subsidiary or minor decisions, and in turn were likely to have links with other strategic decisions, including past and future decisions (Hickson et al, pp. 28 and 195).

If the implementation phase is included in the decision process, then the decision process can take even longer, especially for complex decisions involving distinctive competences and interrelationships at several levels in the organization. Teece, Pisano and Shuen (1997) give the example of the introduction of lean production as one such complex process, and Aitken et al (2007) look at one case of a re-engineering decision for a lighting company where the implementation and operation of lean production took place over four years.

Alliancing and product development are the other two examples of dynamic capabilities cited by Eisenhardt and Martin, in many respects the characteristics of the decision processes these capabilities can be expected to support are similar to those identified by Hickson et al, perhaps not surprisingly since alliancing and major product development can themselves be regarded as forms of strategic decisions in many cases.

An example of an alliance decision is provided by Mitsubshi Electric ${ }^{11}$ and Boeing who announced a strategic alliance in 2001, this broadening and deepening co-operation between the two companies that had already built up over previous years. Like most of their major rivals, Boeing and Mitsubishi had dynamic capabilities in alliancing (though Boeing had perhaps been less willing in the past in terms of forming partnership agreements rather than more straightforward outsourcing deals). While alliancing capabilities were clearly critical to the creation and maintenance of the strategy, the aspects of the alliance that rivals would have found it more difficult (or impossible) to replicate was the rich and varied menu of technological and market resources that both 
parties brought to the table (again consistent with Eisenhardt and Martins' arguments). These resources included Boeing's market base in North America and Mitsubshi's in Japan, with the technologies covering space-based communications, air traffic management, multimedia, navigation, space and communications services, launch services, and space infrastructure (Boeing, 2001).

In the case of dynamic capabilities for product development, another part of the Mitsubishi keiretsu, Mitsubishi Corporation, recently established a "Business Innovation Group” (see Figure 1 below) to help development of new business fields with an explicit medium and long-term perspective. For some activities such as new energy and environmental projects it sets out to integrate efforts scattered throughout the company ${ }^{12}$.

These then are the kinds of decisions that dynamic capabilities have to foster. These decisions typically take months or even years, can involve numerous units and individuals, can trigger numerous subsidiary decisions, and typically connect with other strategic decisions, past, present and future. These bear no resemblance in form or content to decisions as individual choice as typified by most economic frames of reference. But if that is how resources are allocated in these contexts, then that is what economics must study if economics is to live up to its claim to be; "the study of how society manages its scarce resources” (Mankiw, 1997, p. 4). The answer is not to ignore the existence of these phenomena, or to misrepresent them as something they are not.

In the next section we shall look at how principles of nondecomposability or partial decomposability come into play here also.

\section{Dynamic capabilities and Decisions as Systems}

Consider the words "aggregate” and "system”, which if you input into an English version Word document will pass the spellchecker. Now switch the last letters of both words so we now have "eggregata" and "mystes". The spellchecker immediately warns us to look at these two words again, it does not recognise eggregata and mystes. The reason is obvious. Aggregate and system are meaningful words in English, eggregata and mystes are not. To put it another way, words are systems in which the order and pattern of relationships of the components (the letters) one to another matter to the sense of the resulting word, words are not simple sum totals of component letters. If they were, we could equally describe a word as an "aggregate”, an "eggregata”, or "a great egg” of letters - each option would be equally meaningful, as would be the thought provoking; “eat egg rag”.

That might be discounted as a simple trick with words, but the important thing in the present context is whether or not it also applies to dynamic capabilities, either individually or collectively. Do order and pattern matter in terms of the role that dynamic capabilities play in organisational behaviour, or can the whole be treated as the simple sum of parts? If the answer is the latter, it will considerably simplify our task, indeed it would signal that routes to uncovering the sources of competitive advantage may lie in analysis of individual components, such as unique assets, distinctive capabilities and core 
competencies. It would also comfortably mesh with the reductionist orthodoxy in economics which emphasises individual actions and typically treats higher levels as the aggregation of lower levels.

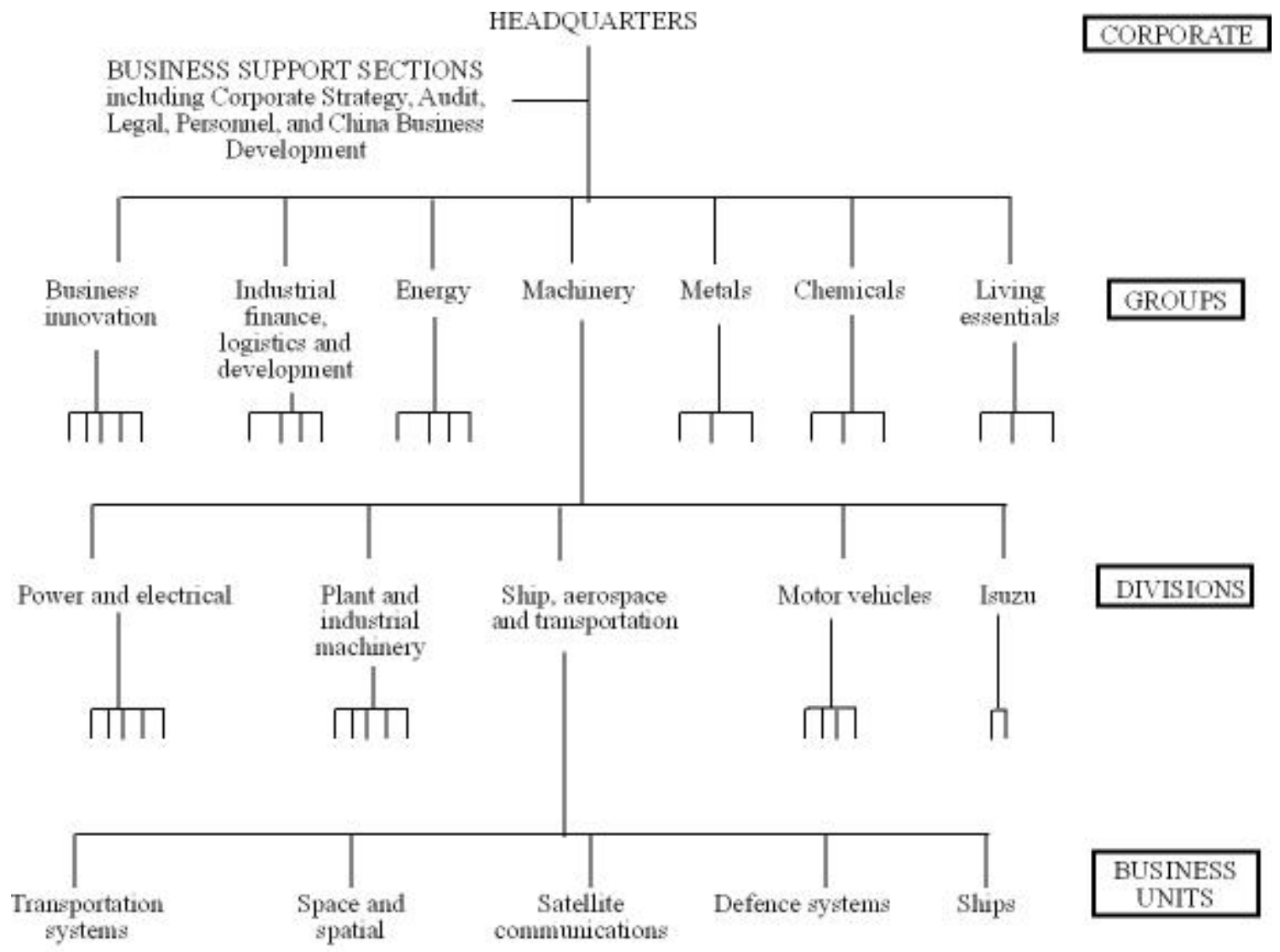

Figure 1: Partial and limited organization structure for Mitsubshi Corporation

Source: based on published company information

But order and pattern do matter. The most obvious clue is visual, as represented in organisational charts. For example, in 2007 Mitsubishi Corporation was organised into 157 business units assigned to 27 separate divisions, which in turn were arranged by 7 groups which reported to HQ. The HQ was also assisted by 19 corporate staff sections. Figure 1 shows a partial and simplified organisational chart for Mitsubishi Corporation in 2007.

If order and pattern did not matter, then we could shuffle and swap Mitsubishi's divisions and business units around to different homes. It clearly would matter whether the Satellite Communications Business Unit is located within the Ship, Aerospace and Transportation Division or within the Chemicals Division, while an Apparel Business Unit that has found a congenial home within the Lifestyle Division of the Living Essentials Group 
might find it difficult to explain its problems and needs if it suddenly found itself rubbing shoulders with fuel business units and divisions within the Energy Group.

Obviously order and pattern matter in the case of organization design, but it is one thing to recognise this, quite another to incorporate it into analysis. It might be thought that the economics approach to hierarchies would recognise these issues and bring them centre stage, but typically they do not. The "markets and hierarchies" approach as developed in the eponymous book by Williamson (1975, pp.132-54) does recognise the role of hierarchy as an alternative to markets and also the costs and benefits of alternative forms of hierarchy (such as M-form versus U-form). However, following Coase (1937), the role of hierarchy in such cases tends to be characterized as a means of economising on transaction costs, with even hierarchy itself being characterised in contractual terms (e.g. Williamson, 1985, pp.221-222). Discussion of M-form vs. U-form is not really about pattern, just the advantages of decentralisation and the creation of "natural decision units" in the M-Form. While the latter is some recognition of order and structure, it does not really go anything like far enough.

In cases like Mitsubsishi, major similarities and commonalities in terms of resource characteristics between different parts of the firm serve as the basis for the creation of major foci for strategic decision making (such as the Energy Group and the Motor Vehicles Division) and in turn signal nondecomposability or partial decomposability of the system as a whole. It is not just commonalities in terms of resource characteristics that can be form the basis for strategic decisions, complementarities can matter as well, and at the same time, opportunities may arise which do not fit into established decisionmaking boxes and which may require or encourage interaction and co-ordination of activity between different parts of the firm. At the same time, the establishment of settled decision-making units at Group and Division levels around shared marketing and/or technological characteristics (typically signalled by the name of the Group or Division) indicate the significance of this as a basis for organizing strategic decision-making in the diversified firm.

The nature and content of strategic decisions are likely to influence (and in turn be influenced by, the dynamic capabilities that support them. For that reason, the nature of the hierarchical organization of strategic decisions and the role of resource links or linkages (in the form of shared or similar resource characteristics) will matter for the creation and deployment of dynamic capabilities. In practice, the combination, pattern, level and location of links can all help determine the nature and content of strategic decisions. We shall look at each of these issues in turn.

\section{1: The combination of links matters}

The combination of links matters for strategic decisions. Eisenhardt and Martin (2000, p.1117) argue that effective dynamic capabilities have commonalities across firms in terms of key features (popularly termed, 'best practice') so cannot be regarded as persistently heterogeneous across firms (and so specific dynamic capabilities cannot necessarily be regarded as unique to a firm). They argue that dynamic capabilities are not 
themselves sources of long-term competitive advantage. As Winter notes in similar vein; "The concept of dynamic capability is a helpful addition to the tool kit of strategic analysis, but strategic analysis itself remains a matter of understanding how the idiosyncratic attributes of the individual firm affect its prospects in a particular competitive context” (Winter, 2003, p.995).

So where does the potential for long term competitive advantage lie according to Eisenhardt and Martin? They argue it lies in using dynamic capabilities to create resource configurations that have that advantage. They give the example of the acquisition capability of GE Capital (which they note is well known and imitable) but what is far more difficult to duplicate is the resource base of already acquired tightly linked businesses and the related economies of scope among them that GE Capital has created and continues to build. This is echoed in Mitsubishi's Machinery Group statement ${ }^{13}$ of current (2007) strategy whose major aspects they summarise as creating new business models by refining functions in value chains, and also working with the Industrial Finance, Logistics \& Development Group and other Business Groups to develop new finance business models. Just as in the case of GE, it would not be difficult to envisage rivals' replicating individual value chains or functions which are part of the Mitsubshi's strategy, but it can be much more difficult to replicate the whole, especially in a path dependent world where assembling all (or sufficient) pieces of the jigsaw may be difficult or impossible.

In an earlier study of Boeing, Kay and Clarke showed that "the curious success of Boeing in diversifying into missiles" (1999, p.149) could not be explained by identifying any particular competence, distinctive or otherwise. Instead, the explanation for its success was to be found in the totality of linkages it brought to bear on the strategy. This perspective also helps unravel the potential sources of competitive advantage in the Boeing / Mitsubishi Electric alliance discussed above. It would be misleading to analyze the logic for this alliance by considering the elements piece by piece, and indeed it would be surprising if in some parts of the Boeing/Mitsubishi alliance menu their rivals did not have comparable or even superior ingredients. The logic of the alliance has to be looked at as a whole, rather than in terms of component parts.

However, it is not just totality of links that matters, pattern can matter as well as we note in the next section.

\section{2: The pattern of links matters}

Combination of links matters, but combination can take different forms from aggregation through various cases of integration. However, aggregation may not be sufficient, the actual pattern of links can potentially influence several critical issues as far as the firm is concerned, including the nature and location of dynamic capabilities, both within and between firms. As Kogut and Zander (1996) note (with respect to the US) "diversification tends to follow consistent patterns” (p.513). 
Figure 2 below shows some complex strategies based on three different 9-unit diversified firms. In each case there are links in the form of shared technological resources (the black links) and/or shared marketing and distribution resources (the white links) between some or all of the business units. They are classified as related constrained (single link) relatedlinked (variety of links) or conglomerate/unrelated (no individual links or set of links over a significant range of the firm), broadly consistent with Rumelt's (1986) classifications. So the related-constrained strategy here has a singe technological base, while the related links and conglomerate strategies have three different technological bases, the related-linked strategy also has two pairs of business units exploiting different marketing/distribution links.

If we were to compare the three strategies, then by some aggregative measures there is not all that much difference between the three strategies. In all three cases, the firm has diversified into nine different product markets. The main difference between the relatedconstrained and related-linked strategy is that all its business units are directly linked by the same (technology) thread, while in the related-linked case the linking (market or technology) thread can vary as we move from left to right along the strategy. Then if we were to compare the three strategies in terms of how richly linked their business units are to one another, the unrelated strategy here has no links between its $3^{\text {rd }}$ and $4^{\text {th }}$, and $6^{\text {th }}$ and $7^{\text {th }}$ business units (reading from left to right), while the other two do. The unrelated strategy here is not quite as richly linked as the other two strategies, but only to the extent of two missing links, and this is for a stylised simple case where the three natural groupings only have three business units each

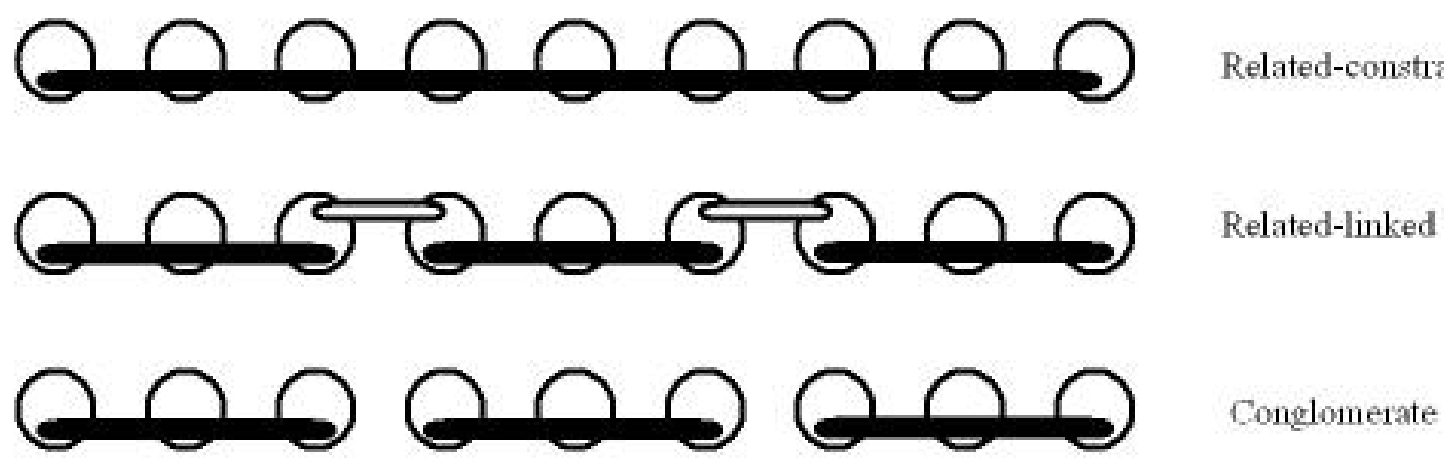

Figure 2: Linkages associated with different diversifcation strategies

In practice, a conglomerate like Mitsubishi can have more than 20 business units linked by shared common marketing or technological characteristics and resources within a single Group (its Machinery Group in Figure 1 actually has 21 business units organized by its five constituent divisions). If describing Mitsubishi as a conglomerate or unrelated strategy is opening up the black box of the firm, it hardly amounts to much more than peeking inside the lid of the box. In general, if a purely aggregative perspective is taken, it can be difficult to argue the case that many conglomerates are much more weakly linked than related diversifiers. 
If degree of linkage may not be as significant a discriminator between strategies as might seem at first sight, does pattern of linkages matter? Rumelt's (1986) analysis suggests it does matter, and Kay (1997) looks as at these issues in a dynamic context, with the nature of linkages providing not only a basis for internal economies and learning opportunities, but also a potential source of vulnerability to external threats. Pattern of links has significant implications for static and dynamic efficiency, internal organization and the potential impact of Schumpeterian waves of creative destruction. Indeed, system and pattern may also be intrinsic to the higher level of the dynamic capability itself, as reflected in Zollo and Winters' description; “a dynamic capability is a learned and stable pattern of collective activity through which the organization systematically generates and modifies its operating routines in pursuit of improved effectiveness (2002, p. 340).

It is not just important to see the firm as a partly decomposable or nondecomposable entity, it is how these parts link together than matters, just as it does for the architecture of a building, or the structure of a molecule.

\section{3: The level of links matters}

It is not just combination and pattern of links that matter for strategic decision, the level of links matter as well, the role of hierarchy is to help organizations sort out activities into groups of nested clusters (Kay 1997, pp. 228-246). In the case of Mitsubishi Corporation in Figure 1, the exploitation of links can be seen at several levels in the corporation. The names of the Mitsubishi's Groups (e.g. Living Essentials; Chemicals; Machinery), Divisions (e.g. Petroleum; Steel, Home Care) and Business Units (e.g. Aluminium; Fertiliser; Dairy Foods), tend to be a guide to whether the links being exploited are predominantly in technology, in marketing/distribution, or in a combination of categories. While our jury might still be out as to whether each of these levels represents a nearly decomposable system, (as opposed to merely a partly decomposable system), the various Group, Division and Business Unit names signify what makes these levels only "nearly" or "partly" decomposable and prevents them from being treated as fully decomposable aggregative systems

The 157 business units of the Mitsubishi Corporation are mostly concerned with the management of value chains and the integration (and complementarity) of functions (such as sales, production, purchasing) that contribute to the value chains. After that, organization of decision-making is generally by commonality of activity rather than complementarity, and in general, commonalities tend to diminish as we move up the hierarchy. Lower level co-hosted Business Units such as "Space \& Spatial” and "Satellite Communication" can be expected to have more in common than does their parent Division "Ship, Aerospace and Transportation Systems" with the "Power and Electrical Systems" division. In turn, these two Machinery divisions could at least be expected to find more kinship relations between them than would be expected between the "Machinery" and "Living Essentials" Groups. Commonalities weaken and broaden as we move up the hierarchy. Various products in the "Ship" business unit may be richly connected, but much of the connections may be concentrated within that business unit. On the other hand, even if there are mostly only some weak R\&D links shared at Group 
level within the Machinery Group, some of these links could span many or all of the 21 Business Units comprising the Group.

In the case of Mitsubishi, there are still thin threads between Groups coordinated by Headquarters, one indicator of this is the varied set of Corporate Staff Sections which includes Corporate Strategy, Audit, Legal, Personnel, and China Business Development sections. If there were no links at all between groups, these boxes would be empty. Even at the highest level where Mitsubishi might be regarded as a "nearly decomposable" system, the "nearly" part still matters.

Further, more than one level may be involved in creating and maintaining competitive advantage. Teece, Pisano and Shuen (1997) following Henderson and Clark (1990) and Womack, Jones and Roos (1991) note that systems-level or 'architectural' innovations often require new routines to integrate and coordinate engineering tasks, and a systemic innovation like lean production may require the integration of distinctive processes all the way down from higher order management level to the shop floor.

The nature of dynamic capabilities is likely to be level-dependent in so far as their role in enabling strategic decisions that involve links or sets of links has to be sensitive to the level or levels of the organisations involved. This also raises the issue of where dynamic capabilities such as in strategic decisions, alliancing and product development are to be found. Are they embodied at senior level in the corporation or diffused and distributed throughout the corporation? Are they restricted to just one level, or just one segment of the firm (such as Mitsubishi's Business Innovation Group)? The fact that the answer is not immediately obvious makes it interesting, and it would not be surprising if the answer varied from dynamic capability to dynamic capability, and from firm to firm.

\section{4: The location of links matters}

The location of links may also be important. Analysis might also benefit from challenging the notion that dynamic capabilities should necessarily be regarded as firmspecific. Thirteenth Century Venetian merchants, City of London traders, Antwerp diamond cutters, and Hollywood producers can all be regarded as systems in which requisite capabilities may be diffused and distributed throughout the system, the system in each case being a grouping of firms and/or individuals, and possibly constituting a cluster or part of clusters in the Porter (1990) sense of the word. Indeed, it may be helpful to conceive of such systems as forms of organization in their own right (Pitelis and Kay 2007). The fact that there may be no actual central direction need not disqualify these systems from being considered as organizational forms, any more than some forms of jazz have no need for a conductor (Earl, 1996) It is also possible to conceive of cases of diffused dynamic capabilities that are not necessarily location-specific, such as supply chain management capabilities in the auto industry which can have a club-like quality, with tier 1 suppliers such as Visteon and Delphi aiming to have a supply chain management system built around chosen suppliers, and designed to stimulate innovative activity as well as operational efficiency. 
Three mental experiments might help to test indirectly whether the notion of dynamic capabilities being diffused throughout a multi-firm system is a reasonable one. The first is whether membership of the grouping can be regarded as a source of competitive advantage; is being an Antwerp diamond cutter or a Visteon supplier something that can be regarded by outsiders and potential customers as adding value? If so, then it is reasonable to assume that members may be regarded as possessing high quality capabilities associated with, and possibly contingent on, membership of their group (we immediately concede that this does not mean that these capabilities may necessarily be dynamic capabilities, which is why we now turn to our second and third tests).

The second mental experiment is; would a particular activity or procedure be regarded as a dynamic capability if it was undertaken within a single firm? If so, then it would be reasonable to identify it as a dynamic capability irrespective of its location and distribution. Informal know how trading (Von Hippel, 1987) would seem to qualify as just such a phenomenon. Von Hippel defined informal know-how trading as the extensive exchange of proprietary know-how by informal networks of process engineers in rival (and non-rival) firms. While Von Hippel found evidence that the phenomenon is widely practiced, it was by no means universal, with some firms and sectors avoiding it. Its implementation varied, with top management being aware and supportive of the practice in some cases, and not in other cases.

Schrader (1991) found evidence that participation in informal know-how trading tended to be associated with enhanced performance by the firms concerned. It also appears to have learning and network qualities that can go beyond the pair of firms involved in any bilateral transaction; Von Hippel (1987) raised the possibility that firms could form coalitions with respect to know-how trading and restrict that activity to only a subset of firms in that industry, while Schrader found network effects holding the system together in particular cases; "news about uncooperative behavior of a player appears to travel fast within the surveyed industry. Thus, by not cooperating in one relationship, a player puts several relationships in jeopardy-a strong mechanism for enforcing cooperation”. (1991, p.168). Following later research that includes and goes beyond know-how trading, Von Hippel concludes that it is best to regard the "distributed innovation process as a system" (Von Hippel, 1988, p. 120, italics added), which in a nutshell summaries how dynamic capabilities for change should be regarded.

If and where informal know-how trading is practiced within firms (say, between divisions), it would likely qualify as a potential dynamic capability, with the power to help the firm adapt its skills, resources and competences to a changing environment and enhance its performance. There is no less a justification for treating it as such where it is practiced in the context of a group or network of firms, with the knowledge and experience required to create and maintain such a network (the dynamic capability) diffused and distributed across the constituent firms.

The third mental experiment as to whether the dynamic capabilities can be diffused throughout a multi-firm system is one of simple observation. Groups, networks and alliances tend not to be static, but are frequently characterised by change and turnover of 
members - just as individual firms tend to turnover products, acquire and divest assets. However, if Eisenhardt and Martin are correct in arguing that dynamic capabilities may be necessary (but not sufficient) for sustainable competitive advantage, then a corollary is that any system (whether a firm, group or network) which has demonstrated a reasonable degree of robustness and stability over a sustained period, could be expected to be doing so with the support of some dynamic capability or capabilities. It is not difficult to find cases where coalitions, alliances and networks are unstable and fall apart rather easily, something that might be expected to happen more easily where there is no dynamic capability glue holding the thing together. Conversely, where there are examples of reasonably stable groupings of linkages - whether intra- or inter-firm - these observations suggest that the reasons for sustainability may lie in both dynamic capabilities and the particular configuration of linkages in question.

\section{Conclusions}

One strong conclusion of this paper relates to the limited applicability and usefulness of some established theories of economics in dealing with dynamic capabilities, as well as to broader issues relating to business strategy. We can ground this conclusion with reference to Williamson's comments (1991 and 1996) on the contributions of resource based theory and dynamic capabilities in the context of business strategy. Williamson argues that "what is missing in business strategy, but is desperately needed, is a core theory ... the microanalytic, comparative institutional, economizing orientation of transaction cost economics deals with many of the key issues with which business strategy is or should be concerned .... The economizing approach to strategy should both contribute to and be the beneficiary of these developments (in the new science of organization)” (1996, p. 321).

Leaving aside the perhaps surprising omission of any reference here to the work of Michael Porter (1980; 1985; 1987), the answer to this proposal should be a resounding "no". Williamson argues that "extensions and refinements can be made" to transaction cost economics to help it deal with strategy issues (1996, p.321). However, if the core frame of reference is not designed to help it recognise the central issues here (i.e. process and nondecomposability), then no amount of marginal tinkering will resolve this problem. If you cannot specify the question properly in the first place, then there can be little faith in the answers you generate with your approach. But as we said at the beginning, all this does not negate or even downgrade contributions limited to framing decisions and actions based around individualism and for systems that are at least decomposable in part and/or for some purposes; it just limits their usefulness and applicability to these areas. It is not an example of (for example) transaction cost economics "bad" and systems perspectives "good”, but a question of horses for courses.

That is also not to say that concepts such as bounded rationality, asset specialisation and opportunism may not be central to issues of strategy in general, and dynamic capabilities in particular. Obviously they may be important, just as other concepts neglected or downplayed by transaction cost economics may be important, but these issues are not the preserve of transaction cost economics, and as Williamson himself acknowledges (1996, 
pp.29-53) recognition of concepts central to the transaction cost framework typically predate the modern development of the framework.

These remarks are oriented to transaction cost economics, partly because it is commonly seen as the standard approach to the economics of organization, and partly because of claims such as the above that it could produce the foundations for a core theory in the area (either substituting or complementing the dynamic capabilities perspective). However, it could apply with equal or greater force to many other economic approaches to the economics of organization such as game theory and principal-agent analysis. If the lenses of methodological individualism through which you view the world are incapable of seeing Simon's “great river" of complex decision, then you have no basis for analysing business strategy, especially as far as analysing the nature of core drivers such as dynamic capabilities is concerned.

This is not a pessimistic view of the potential contribution of economic perspectives to this area, on the contrary if one interprets economics as an area of study (allocation of scarce resource) as opposed to a method (methodological individualism), it opens up genuinely new vistas for investigation. Without prejudging the issues, concepts rooted in economics such as scarcity, opportunity cost, rationality and efficiency are also likely to be still important here.

What it does mean is that there may be circumstances in which looking at phenomena from the perspective of both process and system may help illuminate analysis. Properly specifying questions relating to dynamic capabilities of necessity turns around what is involved in strategic decisions, which in turn inevitably involves (or should involve) the complementary roles of nondecomposability and decision processes. The role of knowledge in relation to these capabilities is also a likely to a critical issue (Foss, 2003; Kogut and Zander, 1992 and 1996). As Winter argues, “the process of change in a firm’s way of doing things most typically involves incremental adjustment in a complex, interdependent system” (1991, p.177) ${ }^{14}$ and Langlois (drawing on Simon's analysis of the principles of decomposability in modular design), argues that the firm can be seen as "islands of nonmodularity in a sea of modularity" (2002, p. 34). While Langlois is looking at the firm from the perspective of the partitioning of rights and residual claims, much the same conclusion comes from our looking at the firm from the perspective of decisions, with decisions themselves seen as processes and not just individualistic choices.

Clearly these are issues which are more difficult to model and test than the more tractable problems and simpler perspectives associated with traditional economic approaches to the economics of organisation. But studies such as those by Simon, Loasby, Mintzberg et al, Hickson et al and Cohen et al have helped shine some light on what these decisions look like, while work by many others ${ }^{15}$ have all helped indicate how study of such phenomena might be framed and pursued. Simon was right - the question of who really makes complex decisions is indeed meaningless, and attempts to frame them that way are doomed to fail. It is time to put meaning back into economics of organization, and the 
role and relevance of dynamic capabilities is one key route through which this objective can be pursued. 


\section{References}

Aitken, J., P. Childerhouse, M. Christopher and D. Towill (2007) Designing and managing multiple supply chains, unpublished paper.

Boeing (2001) Boeing, Mitsubishi announce strategic alliance, Boeing Press Release June 20

Chandler, A. D. (1977) The Visible Hand: the Managerial Revolution in American Business, Cambridge, Harvard University Press.

Coase, R. H. (1937) The Nature of the Firm, Economica, 4, 386-405.

Channon, D. F. (1973) The Strategy and Structure of British Enterprise, London, Macmillan.

Cohen, M. D. March, J. G. and Olsen J. P. (1972) A garbage can model of organizational choice, Administrative Science Quarterly, 17, 1-25.

Dosi, G, (1982) Technological paradigms and technological trajectories, Research Policy, $11,147-62$.

Dosi, G., Teece, D.J. and Winter, S. (1992), Toward a theory of corporate coherence: preliminary remarks in G. Dosi, R. Gianetti and P.A. Toninelli (eds), Technology and Enterprise in an Historical Perspective, Oxford: Clarendon.pp. 185-211.

Dyas G. P. and Thanheiser H. T. (1976) The Emerging European Enterprise: Strategy and Structure in French and German Industries, London, Macmillan.

Earl, P. E. (1996) Contracts, coordination and the construction industry, in Earl. P. E. (ed.) Management, Marketing and the Competitive Process, Cheltenham, Edward Elgar 149-71.

Eisenhardt, K. M. and J. A. Martin (2000) Dynamic capabilities: what are they? Strategic Management Journal, 21, 1105-1121.

Foss, N. J. (2003) Bounded rationality and tacit knowledge in the organizational capabilities approach: an assessment and a re-evaluation Industrial and Corporate Change, 12, 185-201.

Gresov, C. and R. Drazin (1997) Equifinality: Functional Equivalence in Organization Design. Academy of Management Review 22: 403-428.

Helfat, C. E. and M. A. Peteraf, The dynamic resource-based view: capability lifecycles, Strategic Management Journal, 24, 997-1010 
Henderson, R. M. and K. B. Clark (1990), Architectural innovation: the reconfiguration of existing product technologies and the failure of established firms, Administrative Science Quarterly, 35, 9-30.

Hickson, D. J., R. J. Butler, D. Cray, G. R. Mallory and D. C. Wilson (1986), Top Decisions: Strategic Decision-making in Organizations. Jossey Bass: San Francisco, CA.

Kay, N. M. (1977) The Allocation of Resources to Research and Development in the Firm, Ph.D thesis, Economics Department, University of Stirling

Kay, N. M. (1979) The Innovating Firm: A Behavioural Theory of Corporate R \& D, Macmillan London; St Martins Press, New York.

Kay, N. M. (1997) Pattern in Corporate Evolution, Oxford, Oxford University Press.

Kay, N. M. (1999) Loasby and decisions: A non-Coasian perspective on the nature of the firm, In S. Dow and P. Earl (eds) Contingency, Complexity and the Theory of the Firm, Edward Elgar, London, 67-91.

Kay, N. M. (2000) Searching for the firm: the role of decision in the economics of organizations”, Industrial and Corporate Change, 9, 683-707.

Kay, N. M. (2008) Reappraising the Nature of the Firm: The Role and Influence of Lexical and Structural Ambiguity, Organization Studies, forthcoming

Kay, N. M. and P. Clarke (1999) Boeing, corporate strategy and technological change, in Kay, N. M. The Boundaries of the Firm, London, Macmillan, pp. 129-58

Kogut, B., and U. Zander (1992) Knowledge of the firm, combinative capabilities, and the replication of technology. Organization Science, 3, 383-397.

Kogut, B., and U. Zander (1996) What firms do? Coordination, identity, and learning. Organization Science, 7, 502-518.

Langlois, R. N. (1992), Transaction cost economics in real time, Industrial and Corporate Change, 1, 99-127.

Langlois, R. N. (2002) Modularity in technology and organization, Journal of Economic Behavior and Organization, 49, 19-37.

Langlois, R. N. and Robertson, P. L. (1995) Firms, Markets and Economic Change, London, Routledge.

Loasby, B. J. (1967) Long-range formal planning in perspective, Journal of Management Studies 4, 300-308. 
Mankiw, N. G. (1998) Principles of Economics, Orlando, Dryden Press.

March, J. G. and J. P. Olsen (eds.) (1976) Ambiguity and Choice in Organizations, Bergen, Universitetsforlaget.

Mintzberg, H., D. Raisinghani and A. Theoret (1976), 'The Structure of "Unstructured" Decision Processes,' Administrative Science Quarterly, 21, 246-75

Nelson, R. R. and Winter, S. G. (1982) An Evolutionary Theory of Economic Change, Cambridge Mass. Harvard University Press.

Newall, A. and H. A. Simon (1972) Human Problem Solving, Englewood Cliffs, New Jersey, Prentice Hall.

Olsen, J. P. (1976a) Choice in an organized anarchy, in, J. G. March and J. P. Olsen (eds.) (1976) 82-139

Olsen, J. P. (1976b) Reorganization as a garbage can, in, J. G. March and J. P. Olsen (eds.) (1976) 314-337.

Penrose, E. T. (1959) The Theory of the Growth of the Firm, Oxford, Blackwell.

Pitelis, C. and N. M. Kay (2007) On the nature of forms of economic organization and "clusters": Some potential for cross-fertilization, unpublished paper

Porter, M. (1980) Competitive Strategy: Techniques for analyzing Industries and Competitors, New York, Free Press.

Porter, M. (1985) Competitive Advantage: Creating and Sustaining Superior Performance, New York, Free Press.

Porter, M. (1987) From competitive advantage to competitive strategy, Harvard Business Review, May/June 43-59.

Porter, M. (1990) The Competitive Advantage of Nations, London, Macmillan.

Richardson, G. B. (1972) The organisation of industry, Economic Journal, 82, 833-96.

Rumelt, R. P. (1984) Towards a strategic theory of the firm, in R. B. Lamb (ed.) Competitive Strategic Management, Englewood Cliffs, New Jersey, Prentice Hall, 556-70.

Rumelt, R. P. (1986) Strategy, Structure and Economic Performance, 2nd edn. Boston, Harvard Business School.

Samuelson, P. A. (1976) Economics, $10^{\text {th }}$ edition, New York, McGraw-Hill Kogakushi 
Samuelson, P. A. and W. D. Nordhaus (1985) Economics, New York, McGraw-Hill Schrader, S. (1991). Informal technology transfer between firms: Cooperation through information trading. Research Policy, 20, 153-170.

Schumpeter, J. A. (1942) Capitalism, Socialism and Democracy, New York, Harper and Row.

Simon, H. A. (1955) A behavioral model of rational choice, Quarterly Journal of Economics, 69, 99-118.

Simon, H. A. (1964) On the concept of organizational goal, Administrative Science Quarterly, 9, 1-22.

Simon, H. A. (1976) Administrative Behavior: a Study of Decision-Making Processes in Administrative Organization, $3^{\text {rd }}$ edn, New York, Free Press.

Simon, H. A. (1981) The Sciences of the Artificial, 2nd edn. Cambridge, MIT Press.

Teece, D. J. (1986a), Profiting from technological innovation, Research Policy, 15, 286-305.

Teece, D. J. (1986b) Transaction cost economics and the multinational enterprise: an assessment, Journal of Economic Behavior and Organization, 7, 21-45.

Teece, D. J., R. P. Rumelt, G. Dosi and S. Winter (1994) Understanding corporate coherence: Theory and evidence Journal of Economic Behavior and Organization, 23, 130

Teece, D. J. and G. Pisano (1994) The dynamic capabilities of firms: an introduction, Industrial and Corporate Change, 3, 537-56.

Teece, D. J., G. Pisano and A. Shuen (1997) Dynamic capabilities and strategic management, Strategic Management Journal, 18, 509-533.

Von Hippel, E. (1987) Cooperation between rivals: informal know-how trading, Research Policy, 16, 291-302.

Von Hippel, E. (1988) The Sources of Innovation, Oxford, Oxford University Press.

Whittington, R. and M. Mayer (2000) The European Corporation: Strategy, Structure and Social Science, Oxford, Oxford University Press.

Williamson, O. E. (1975) Markets and Hierarchies: Analysis and Antitrust Implications, New York, Free Press

Williamson, O. E. (1985) The Economic Institutions of Capitalism: Firms, Markets, Relational Contracting, New York, Free Press. 
Williamson, O. E. (1991) Strat egizing, Economizing, and Economic Organization Strategic Management Journal, 12, 75-94.

Williamson, O. E. (1996) The Mechanisms of Governance, Oxford, Oxford University Press.

Winter, S. G. (1988) On Coase, Competence, and the Corporation, Journal of Law, Economics and Organization, 4, pp. 163-80

Winter. S. G. (2003) Understanding dynamic capabilities, Strategic Management Journal, 24, 991-95

Womack, J., D. Jones and D. Roos (1991) The Machine that Changed the World. HarperPerennial, New York

Zahra, S. A., H. J. Sapienza and P. Davidsson (2006), Entrepreneurship and Dynamic Capabilities: A Review, Model and Research Agenda. Journal of Management Studies 43, 917-955.

Zollo, M. and S. G. Winter (2002) Deliberate learning and the evolution of dynamic capabilities, Organization Science, 13, 339-351.

\section{ENDNOTES}

\footnotetext{
${ }^{1}$ The award of the 2002 Noble Prize in Economics to Daniel Kahneman (jointly with Vernon Smith) might seem an interesting exception to this general argument. At the same time, Kahneman is a research psychologist, not an economist and apparently claimed never to have taken an economics class in his life. Whether this apparent lacuna hindered or helped his research into human decision-making is not clear, though the argument of this paper suggest it may not have been entirely unhelpful.

${ }^{2}$ This chapter was also published as Simon (1964)

${ }^{3}$ Williamson (1996, pp. 37, 44, 235) sees Simon’s contribution as based around highly microanalytic decision premises (which Williamson argues are more microanalytic than if the transaction is invoked as basic unit for analysis), and cites Newell and Simon (1972) work on problem solving as a focal problem for this approach.

${ }^{4}$ Other dedicatees being Kenneth Arrow, Alfred Chandler and Ronald Coase.

${ }^{5} \mathrm{Ph} . \mathrm{D}$ thesis Kay (1977) published as Kay (1979). While I was convinced then that systems theory in general, and the concept of equifinality in particular, were important (and I believe I demonstrated this in my $\mathrm{PhD}$ ), the timing of the research (late Seventies) and my working within economics departments did not make it easy to communicate this, even on the back of empirical research, and with hindsight it is not surprising the research is little known. I was fortunate enough with supportive $\mathrm{PhD}$ supervision (Brian Loasby, Richard Shaw and Alastair Ulph) and doubly fortunate to have Christopher Freeman of SPRU as my external examiner. Beyond that, if I did not know then the problems of communicating such systems concepts to fellow economists, I was soon to discover them whenever I gave an invited seminar or tried to publish an article in an economics journal, and I eventually gave up on such futile attempts. It is gratifying that systems concepts such as equifinality are now widely recognized (albeit still not in economics or by my spellchecker) and I now see myself as lucky and privileged that my early research ever got published at all.

${ }^{6}$ Efficient capital markets are generally described as ones in which security prices fully reflect all information relevant to their value. In its strong-form, all information, including company secrets, are incorporated in security prices.

${ }^{7}$ Act 1 scene 1.
} 
${ }^{8}$ Act 2 scene 2.

${ }^{9}$ Obviously it might be impossible to exactly replicate all the features of Royal Dutch / Shell's capabilities in this area because it might depend on complementary capabilities not easily accessible or assembled together by other companies. We discuss this point further below in the context of Eisenhardt and Martin's point that dynamic capabilities (such as the acquisition capability of GE Tech) may be imitable, but what might be more difficult to replicate is the accumulated resource base that this capability has already provided

${ }^{10}$ Clearly there may be team aspects in the development of such dynamic capabilities, and if so we would expect this to be reflected in market mechanisms, for example the occasional transfer of academic research teams more or less in their entirety from one institutional home to another.

${ }^{11}$ Mitsubishi Electric and Mitsubishi Corporation (which we look at in more detail below) are separate companies though both form part of the broad Mitsubishi Keiretsu, characterised by cross-ownership, interlocking boards of directors and long term business relationships.

${ }^{12}$ Company sources.

${ }^{13}$ Company sources.

${ }^{14}$ See Winter also for a critique of transaction cost economics here and related analysis of the role of methodological individualism

${ }^{15}$ It is almost invidious to aim to provide a reasonably complete set of names here. But Dosi, Foss, Kogut, Langlois, Loasby, Nelson, March, Penrose, Porter, Richardson, Schumpeter, Simon, Teece, Winter and Zander spring to mind in this context. 